\title{
The Effect of Beam Intensity on Temperature Distribution in ADS Windowless Lead-Bismuth Eutectic Spallation Target
}

\author{
Jie Liu, Lei Gao, and Wen-qiang Lu \\ University of Chinese Academy of Sciences, Beijing 100049, China \\ Correspondence should be addressed to Jie Liu; nauty@ucas.ac.cn
}

Received 25 November 2013; Accepted 28 January 2014; Published 19 March 2014

Academic Editor: Li Shengqiang

Copyright ( 2014 Jie Liu et al. This is an open access article distributed under the Creative Commons Attribution License, which permits unrestricted use, distribution, and reproduction in any medium, provided the original work is properly cited.

\begin{abstract}
The spallation target is the component coupling the accelerator and the reactor and is regarded as the "heart" of the accelerator driven system (ADS). Heavy liquid metal lead-bismuth eutectic (LBE) is served as core coolant and spallation material to carry away heat deposition of spallation reaction and produce high flux neutron. So it is very important to study the heat transfer process in the target. In this paper, the steady-state flow pattern has been numerically obtained and taken as the input for the nuclear physics calculation, and then the distribution of the extreme large power density of the heat load is imported back to the computational fluid dynamics as the source term in the energy equation. Through the coupling, the transient and steady-state temperature distribution in the windowless spallation target is obtained and analyzed based on the flow process and heat transfer. Comparison of the temperature distribution with the different beam intensity shows that its shape is the same as broken wing of the butterfly. Nevertheless, the maximum temperature as well as the temperature gradient is different. The results play an important role and can be applied to the further design and optimization of the ADS windowless spallation target.
\end{abstract}

\section{Introduction}

At present, China's nuclear power industry is expanding rapidly and more nuclear power plants are being built to solve air pollution and energy need. Naturally, it will lead to the severe problem of nuclear waste disposal. The accelerator driven system (ADS), shown in Figure 1 [1], aiming at the management and disposal of high level nuclear wastes, is of high cleanliness and safety. So the construction of ADS has been included in the large science and technology fundamental facilities in the twelfth five-year plan of the National Development and Reform Commission (NDRC) of China. The study of ADS has already been carried out systematically for decades in Europe. In earlier designs, a window exists between the proton beam and the target to ensure the accelerator is safe. But the window needs to sustain high-energy proton irradiation and corrosion by the flowing heavy liquid metal in very high temperature and no suitable materials can be used for a long time at present. Therefore, the windowless design is more desirable for it is able to avoid the problems of materials [2].
The thermal hydraulics design of the target is a challenging task, as the space available is very limited and the maximum heat load is about $300 \mathrm{~W} / \mathrm{cm}^{3}$ and the total heat deposit reaches 2.1 MW [1]. Previous works focus on the heat transfer in the spallation target with a window. For example, Nema [3] introduced the Indian roadmap and activities under ADS programme. Mantha et al. [4] proposed an experimental LBE loop for simulating the window thermal load by a high power plasma torch and conjugate heat transfer analysis has been carried out for various window materials, geometry, and flow configuration to determine cooling capability of LBE. Borgohain et al. [5] carried out steady-state natural circulation experimental studies and transient studies for start-up of natural circulation in the loop, loss of heat sink, and step power change. Cho et al. [6] proposed a numerical design study to obtain the optimal design parameters for a 20 MW spallation target for a 1000 MWth ADS and a dual injection tube for a reduction of the LBE flow rate at the target channel. Zanini et al. [7] performed the research of the thermal hydraulics behavior from the neutronic and nuclear aspects during the irradiation in the MEGAPIE 
target at the SINQ Facility of the Paul Scherrer Institute. Vanderhaegen et al. [8] simulated the flow inside the vessel in the MYRRHA project using the renormalization group $k$ - $\varepsilon$ turbulence model by the computational fluid dynamics software FLUENT. Su et al. $[9,10]$ built the water experiment to study the free surface behavior and flow patterns which means the respective distribution of the liquid and vapor phases in the flow channel.

The studies mentioned above are all based on the window spallation target because the heat transfer is relatively easy to carry out as the single phase flow in it. However, the beam intensity will be stronger and stronger with the development of the accelerator in the windowless design as there is no limit to window materials, so it is necessary to carry out the research of heat transfer in ADS windowless spallation target as well as different results with various intensity beams to catch up with the development of the accelerator. Roelofs et al. [11] reviewed the development of ADS windowless spallation target in the experiment and the numerical simulation. But the heat transfer in the heavy liquid metal LBE in the windowless spallation target has not been published as far as authors' knowledge is concerned because of the high difficulty caused by the complicated two-phase flow and its interaction with the proton beam. In this paper, the heat transfer calculation is performed and steady-state and transient temperature distribution is obtained which is very important in the further design and optimization of the ADS windowless spallation target in China.

\section{Numerical Model}

During EUROTRANS the design of the windowless target has been evolved substantially so that the latest design (V0.10, Figure 1) conforms to specifications [1].

The flow is considered to be viscous, incompressible, and turbulent. The dimensionless equations governing the axisymmetric mean flow [12-14] are as follows.

Continuity equation

$$
\frac{1}{x^{j}} \frac{\partial}{\partial x}\left(x^{j} u\right)+\frac{\partial v}{\partial y}=0
$$

momentum equation

$$
\begin{aligned}
\frac{\partial u}{\partial \tau}+\left[u \frac{\partial u}{\partial x}+v \frac{\partial u}{\partial y}\right]= & -\frac{\partial p}{\partial x} \\
& +\frac{1}{x^{j}} \frac{1}{\operatorname{Re}}\left[\frac{\partial}{\partial x}\left(x^{j} v_{\mathrm{eff}} \frac{\partial u}{\partial x}\right)\right. \\
& \left.+\frac{\partial}{\partial y}\left(x^{j} v_{\mathrm{eff}} \frac{\partial u}{\partial y}\right)\right]+S_{u} \\
\frac{\partial v}{\partial \tau}+\left[u \frac{\partial v}{\partial x}+v \frac{\partial v}{\partial y}\right]= & -\frac{\partial p}{\partial y}
\end{aligned}
$$

$$
\begin{aligned}
+\frac{1}{x^{j}} \frac{1}{\operatorname{Re}}[ & \frac{\partial}{\partial x}\left(x^{j} v_{\mathrm{eff}} \frac{\partial v}{\partial x}\right) \\
+ & \left.\frac{\partial}{\partial y}\left(x^{j} v_{\mathrm{eff}} \frac{\partial v}{\partial y}\right)\right]+S_{v}
\end{aligned}
$$

where

$$
\begin{gathered}
S_{u}=\frac{1}{x^{j}} \frac{1}{\operatorname{Re}}\left[\frac{\partial}{\partial x}\left(x^{j} v_{\mathrm{eff}} \frac{\partial u}{\partial x}\right)+\frac{\partial}{\partial y}\left(x^{j} v_{\mathrm{eff}} \frac{\partial v}{\partial x}\right)-2 j v_{\mathrm{eff}} \frac{u}{x}\right], \\
S_{v}=\frac{1}{x^{j}} \frac{1}{\operatorname{Re}}\left[\frac{\partial}{\partial x}\left(x^{j} v_{\mathrm{eff}} \frac{\partial u}{\partial y}\right)+\frac{\partial}{\partial y}\left(x^{j} v_{\mathrm{eff}} \frac{\partial v}{\partial y}\right)\right],
\end{gathered}
$$

where $p$ is the pressure, $v$ is velocity, and $(u, v)$ are the radial and axial mean velocity components. The effective turbulent viscosity $v_{\text {eff }}\left(=1+v_{t, n}\right)$ is calculated using the $k-\varepsilon$ model of turbulence:

$$
\nu_{\text {eff }}=1+c_{\mu} \operatorname{Re} \frac{k_{n}^{2}}{\epsilon_{n}} .
$$

Transfer of the turbulent kinetic energy $k_{n}$, its dissipation rate $\epsilon_{n}$, and the temperature distribution $\theta$ are modeled as follows.

$k$-equation

$$
\begin{gathered}
\frac{\partial k_{n}}{\partial \tau}+u \frac{\partial k_{n}}{\partial x}+v \frac{\partial k_{n}}{\partial y}=\frac{1}{x_{j}} \frac{1}{\operatorname{Re}}\left[\frac{\partial}{\partial x}\left(x^{j} \frac{v_{t, n}}{\sigma_{k}} \frac{\partial k_{n}}{\partial x}\right)\right. \\
\left.+\frac{\partial}{\partial y}\left(x^{j} \frac{v_{t, n}}{\sigma_{k}} \frac{\partial k_{n}}{\partial y}\right)\right] \\
+G_{n}-\epsilon_{n},
\end{gathered}
$$

$\varepsilon$-equation

$$
\begin{aligned}
& \frac{\partial \epsilon_{n}}{\partial \tau}+u \frac{\partial \epsilon_{n}}{\partial x}+v \frac{\partial \epsilon_{n}}{\partial y}= \frac{1}{x_{j}} \frac{1}{\operatorname{Re}}\left[\frac{\partial}{\partial x}\left(x^{j} \frac{v_{t, n}}{\sigma_{\epsilon}} \frac{\partial \epsilon_{n}}{\partial x}\right)\right. \\
&\left.+\frac{\partial}{\partial y}\left(x^{j} \frac{v_{t, n}}{\sigma_{\epsilon}} \frac{\partial \epsilon_{n}}{\partial y}\right)\right] \\
&+\frac{\epsilon_{n}}{k_{n}}\left(C_{1 \epsilon} G_{n}-C_{2 \epsilon} \epsilon_{n}\right),
\end{aligned}
$$

energy equation

$$
\frac{\partial \theta}{\partial \tau}+u \frac{\partial \theta}{\partial x}+v \frac{\partial \theta}{\partial y}=\frac{1}{x_{j}} \frac{1}{\operatorname{RePr}}\left[\frac{\partial}{\partial x}\left\{x_{j}\left(1+\alpha_{t, n}\right) \frac{\partial \theta}{\partial y}\right\}+S_{\theta}\right],
$$

where $S_{\theta}$ is the heat source term.

Production

$$
\begin{aligned}
G_{n}=\frac{v_{t, n}}{\operatorname{Re}}[2 & \left\{\left(\frac{\partial u}{\partial x}\right)^{2}+\left(\frac{\partial v}{\partial y}\right)^{2}+j\left(\frac{u}{x}\right)^{2}\right\} \\
+ & \left.\left(\frac{\partial u}{\partial y}+\frac{\partial v}{\partial x}\right)^{2}\right],
\end{aligned}
$$




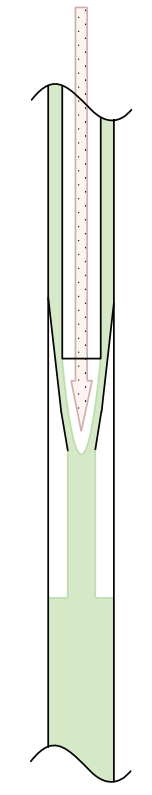

Windowless target design

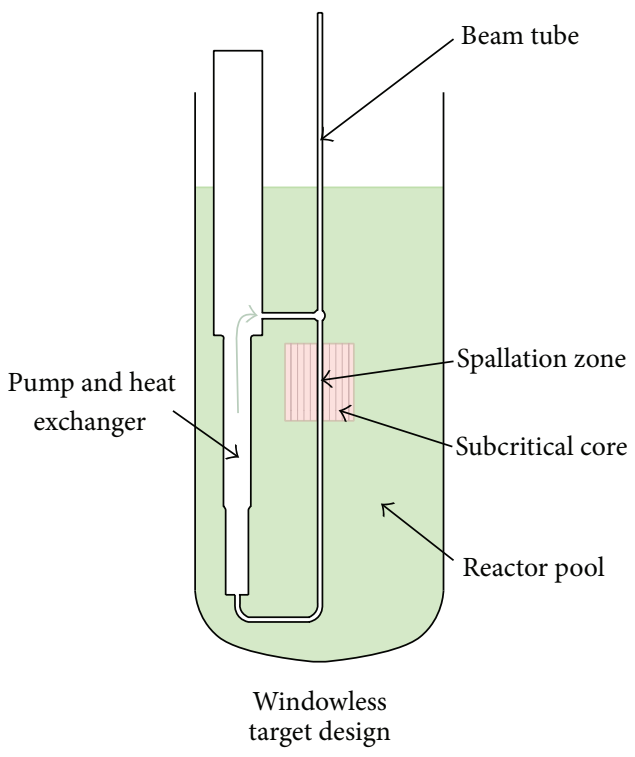

(a)
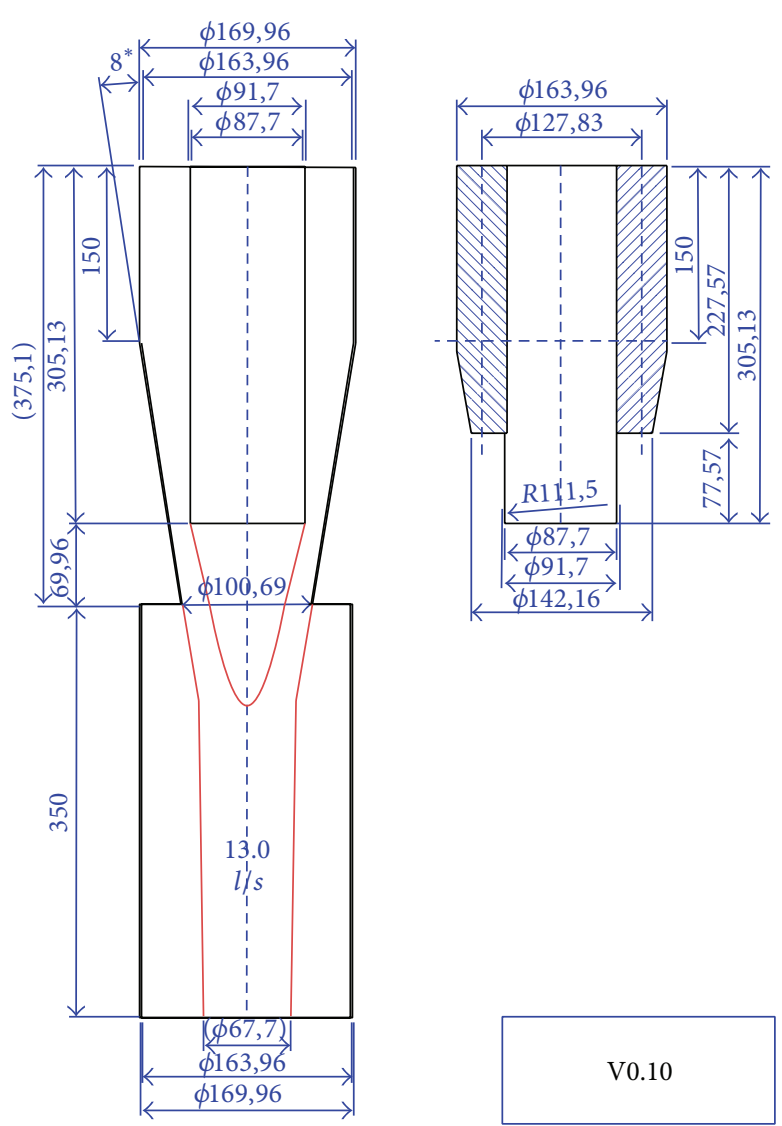

(b)

FIGURE 1: Schematic view of spallation target in the ADS (a) and construction of target (b) [1].

where $G_{n}$ is the production term. Finally, $v_{t, n}$ and $\alpha_{t, n}$ can be written as follows:

$$
v_{t, n}=C_{\mu} \operatorname{Re} \frac{k_{n}^{2}}{\epsilon_{n}} ; \quad \alpha_{t, n}=C_{\mu} \operatorname{Re} \frac{\operatorname{Pr} k_{n}^{2}}{\sigma_{t} \epsilon_{n}} .
$$

Here, $C_{\mu}=0.09, \sigma_{k}=1.0, \sigma_{\varepsilon}=1.3, \sigma_{t}=0.9, C_{1 \varepsilon}=1.44$, and $C_{2 \varepsilon}=1.92$.

According to the work by Batta and Class [15], volume of fluid (VOF) [16] combining with the cavitation is an appropriate numerical model to capture the free surface between the LBE liquid and LBE vapor. Therefore, the $k$ $\varepsilon$ turbulence model, the VOF method, and the cavitation model are used to simulate the flow in the target. With correct physical parameters of LBE and appropriate boundary condition, the steady-state flow pattern of the LBE liquid and vapor has been captured by the authors [17-19] and shown in Figure 2. LBE liquid flows downwards through an annular feeder line surrounding the beam tube and will form a conical free surface which is subjected to the proton beam in early structure. Then, the use of wider guide tubes will result in a detachment zone near the guide tube and the second free surface forms. According to the design for the MYRRHA proton beam [20], the proton beam is circular and energy and maximum intensity are equal to $600 \mathrm{MeV}$ and $4 \mathrm{~mA}$ in continuous wave mode, respectively. The spallation reaction between the LBE and the proton beam is simulated using Monte Carlo radiation transport code that tracks particles.

To obtain heat deposition, the steady-state flow pattern and the nuclear cross section data libraries are introduced into nuclear physics simulation and the result is shown in Figure 3. Then, the initial temperature of the whole domain is set to be $723 \mathrm{~K}$ and the boundary conditions are given (Figure 4). Finally, the heat deposition is introduced into the energy equation in the CFD in order to gain the temperature distribution in the ADS windowless spallation target.

\section{Numerical Results}

3.1. Temperature Distribution. As larger beam intensity may cause boiling of LBE or other instable phenomena, smaller beam intensity is preferred in obtaining different temperature distribution with different beam intensity and $3 \mathrm{~mA}$ is chosen to compare with $4 \mathrm{~mA}$. Figure 5 shows the temperature distribution at the initial time. The temperature distribution is the same as the shape of the heat deposition after taking logarithm calculation. So the heat deposition calculated from the nuclear physics simulation is correctly introduced into the CFD calculation. What is more, maximum temperature occurs near the initial contact surface of proton beam and LBE. It can be inferred that the heat deposition plays a leading 


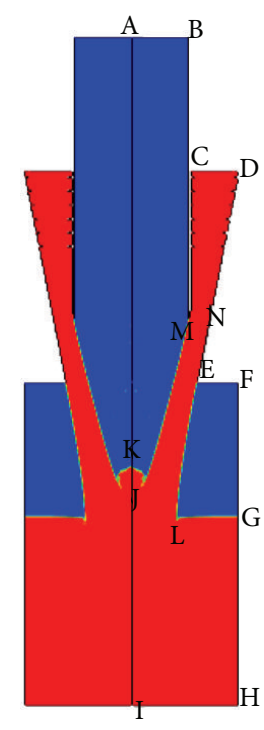

FIGURE 2: Steady-state flow pattern (red: LBE liquid; blue: LBE vapor).

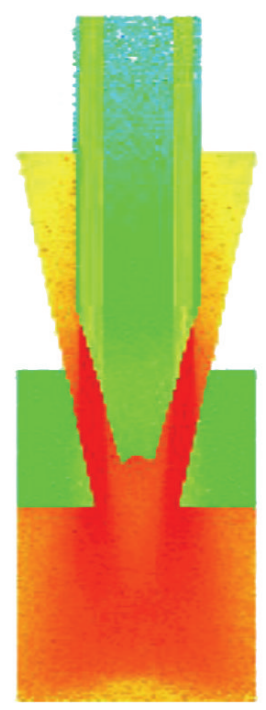

FIgURE 3: Schematic of the heat deposition in the LBE.

role in the forming of the temperature distribution at the very beginning instead of the flow of liquid metal LBE because the characteristic time scale of the spallation reaction is several magnitudes smaller than that of fluid flow and heat transfer by flow should be omitted. Therefore, the heat deposition can be regarded as the constant volumetric heat sources in the simulation of the flow process and heat transfer.

The temperature distribution varying with time while the spallation reaction takes place and fluid flows is shown in Figure 6. As can be seen, the maximum heat load at the contact surface is transferred to the downstream and then the temperature on the two-side free surface near the wall rises because of the flow of the LBE vapor. The temperature is higher near the free surface compared to other area. While the temperature of the LBE liquid at the outlet is very low near

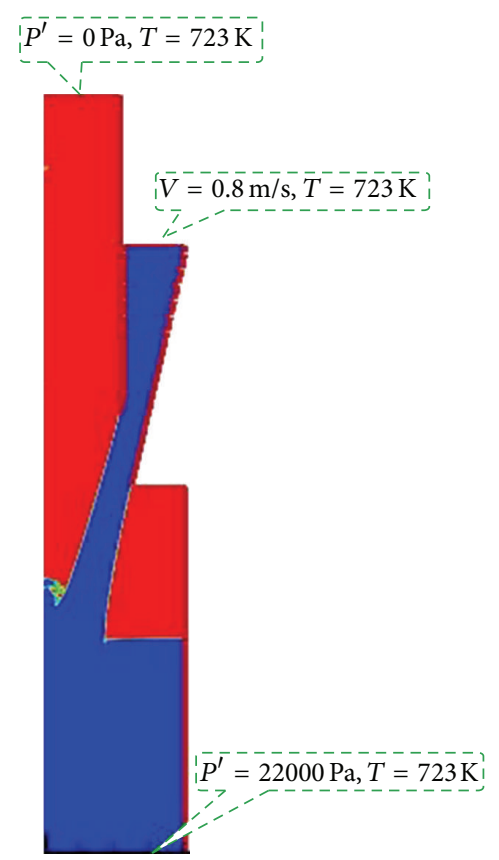

FIGURE 4: The initial temperature and boundary conditions.

the wall. Finally, the maximum temperature which occurs in the LBE liquid under the two-side free surfaces rises to about $815 \mathrm{~K}$ and the distribution is like the shape of broken wings of the butterfly.

3.2. Physical Analysis. The formation of the steady-state temperature distribution is the result of the heat deposition combined with the flow of the heavy liquid metal liquid and vapor, shown in Figure 7. As mentioned before, the distribution of heat deposition (Figure 7(b)) is formed according to the steady-state flow pattern (Figure 7(a)). It is one of the main reasons of the formation of such a temperature distribution that the area of high temperature in the steadystate temperature distribution (Figure 7(c)) just corresponds to the area of a relatively large intensity of the heat deposition on the basis of the comparison between the heat deposition and the steady-state temperature distribution (Figure 7(b)). In addition, another reason is the effect of fluid flow shown in the distribution of streamline (Figure 7(d)) and absolute magnitude of axial velocity (Figure 7(e)). It is illustrated that there is a clockwise vortex in the left side and an anticlockwise vortex in the right side of the streamline (Figure $7(\mathrm{~d})$ ) so that the large intensity of the heat deposition (Figure $7(\mathrm{c})$ ) near to the free surface will transfer toward the area of high temperature in the steady-state temperature distribution. So the high temperature area distributes on the free surface on both sides and the temperature distribution is just like Figure 7(c) shown eventually.

3.3. Comparison between $3 \mathrm{~mA}$ and $4 \mathrm{~mA}$. The authors [18] have calculated the temperature distribution while the beam intensity is $4 \mathrm{~mA}$. Compared with that, the different temperature distribution at the initial time is shown in Figure 8. It can 


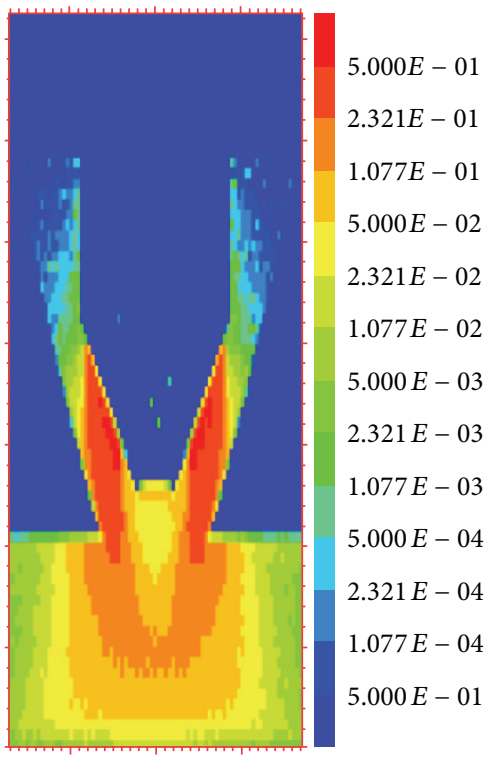

(a)

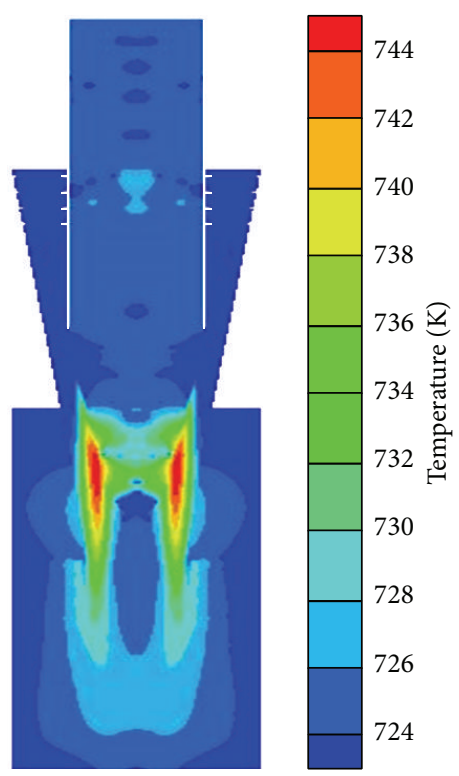

(b)

FIGURE 5: The heat deposition (a) and temperature distribution at the initial time $(t=0.1 \mathrm{~s})(\mathrm{b})$.

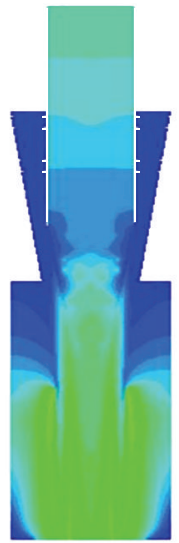

$1.0 \mathrm{~s}$

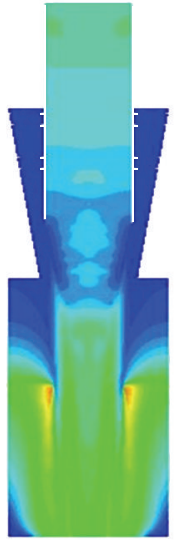

$2.0 \mathrm{~s}$

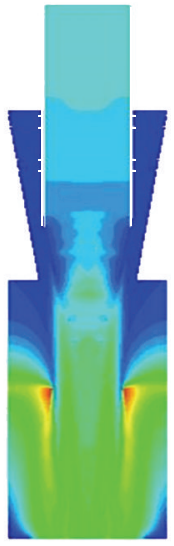

$3.0 \mathrm{~s}$

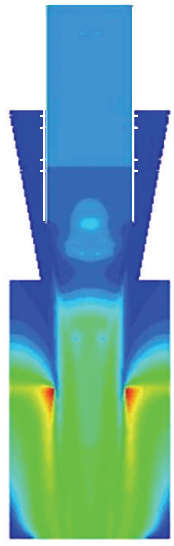

$4.0 \mathrm{~s}$

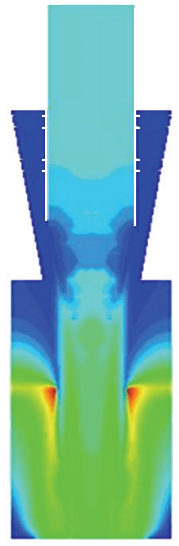

$5.0 \mathrm{~s}$

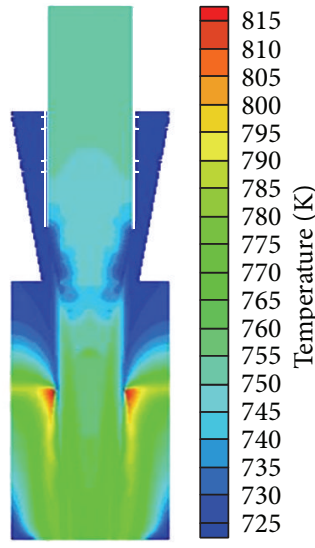

$6.0 \mathrm{~s}$

FIgURE 6: Temperature distribution varies with the time in $3 \mathrm{~mA}$.

be seen that the shape of the distribution is the same while the maximum temperature at $3 \mathrm{~mA}$ is a little lower than that at $4 \mathrm{~mA}$. To figure out how the temperature distribution of different beam intensity varies with time, the comparison at the time of $3 \mathrm{~s}$ and $6 \mathrm{~s}$ is given in Figure 9, respectively. Just like that at the initial time, the shape is almost the same. However, the maximum temperature is about $35 \mathrm{~K}$ higher while the beam intensity is $4 \mathrm{~mA}$ compared to $3 \mathrm{~mA}$. Besides, the temperature distribution in the area of vapor is different as well (Figure 10). It is concluded that stronger beam intensity will lead to larger area of high temperature in the area of vapor located at the top of the target (zone "1" in Figure 10). Furthermore, it shows that the temperature gradient at $3 \mathrm{~mA}$ is smaller in the area of the vapor on the free surface (zone " 2 " in Figure 10). These results confirm the conclusion that the beam intensity has no effect on the shape of the temperature distribution while making a big difference to the temperature value and stronger beam intensity leads to higher temperature and temperature gradient.

3.4. Maximum Temperature. Figure 11 shows the maximum temperature varying with the different beam intensity. It indicates that the maximum temperature at $3 \mathrm{~mA}$ is always lower than that at $4 \mathrm{~mA}$ at the same time. What is interesting is that the variation of maximum temperature at $3 \mathrm{~mA}$ is gentler while that at $4 \mathrm{~mA}$ has a steady state from the very beginning to about $1 \mathrm{~s}$ and then the maximum temperature starts to rise. It is inferred that the very large heat deposition loaded plays a leading role compared with fluid flow at the beginning and it results in the initial variation at $4 \mathrm{~mA}$. Afterwards, the temperature distribution will result from the common effect between heat deposition and fluid flow. When it refers to the variation at $3 \mathrm{~mA}$, the heat deposition and fluid flow have an effect on the heat transfer in the windowless 


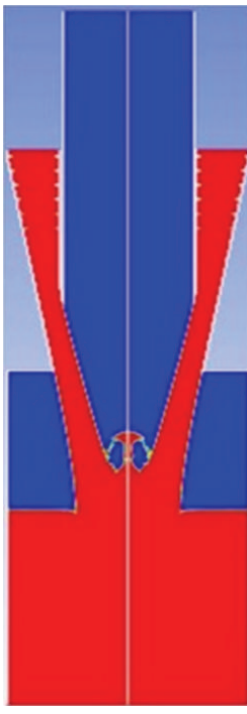

(a)

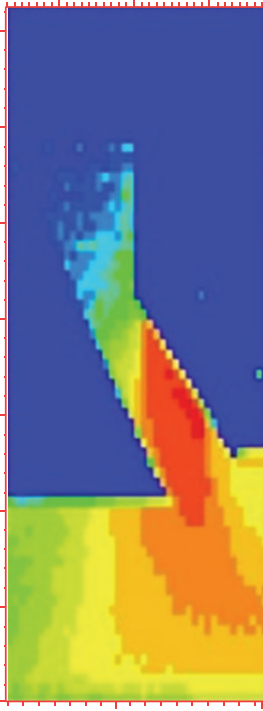

(b)

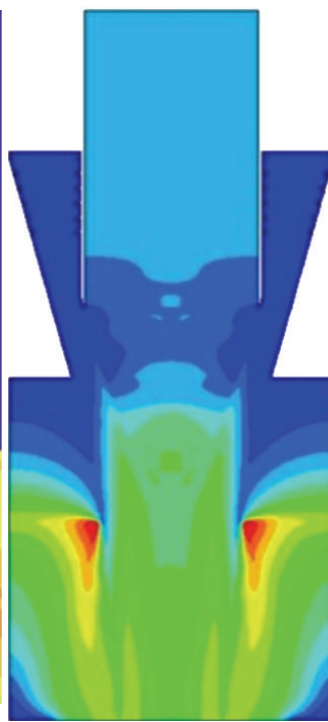

(c)

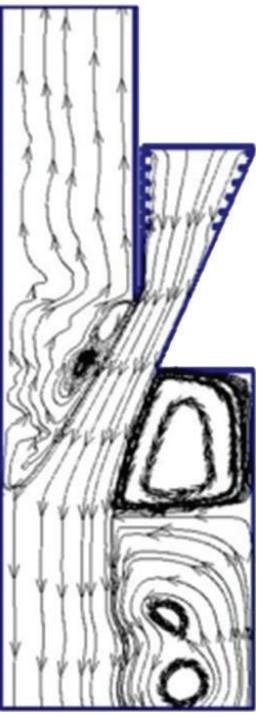

(d)
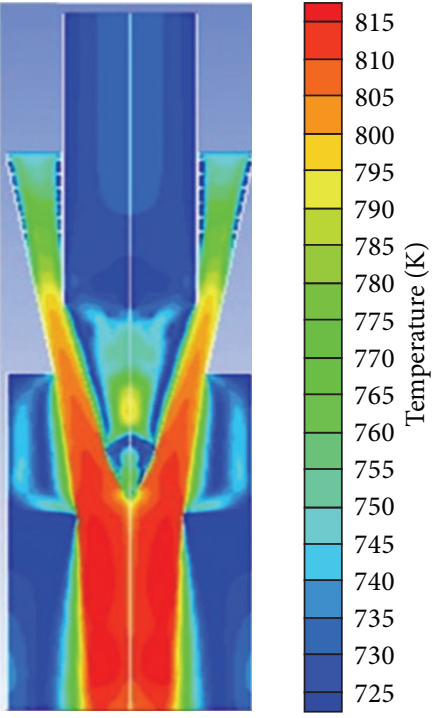

(e)

FIGURE 7: Distributions from left to right: (a) flow pattern; (b) heat deposition; (c) steady-state temperature distribution; (d) streamline; (e) absolute magnitude of axial velocity.
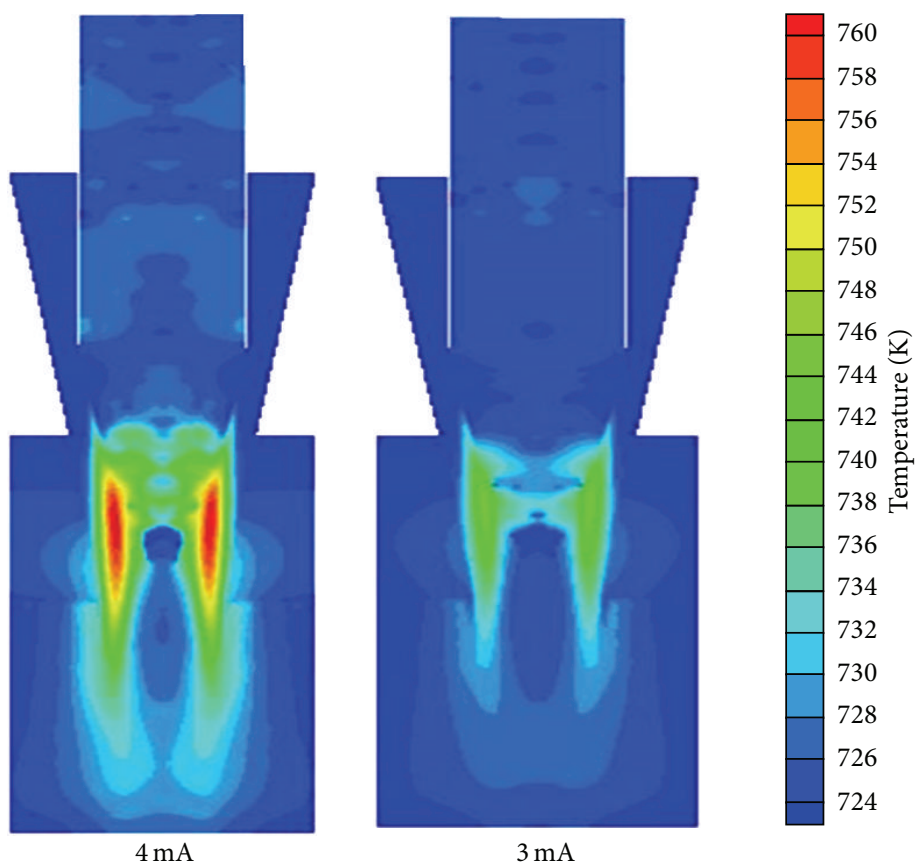

FIGURE 8: Initial temperature distribution varies with the beam intensity $(t=0.1 \mathrm{~s})$.

spallation target together all the time as the heat deposition is smaller. When it reaches the steady state, the maximum temperature at $3 \mathrm{~mA}$ is about $815 \mathrm{~K}$ while at $4 \mathrm{~mA}$ it is $848 \mathrm{~K}$. The beam intensity is identified as follows:

$$
N \times q_{p}=I \times t,
$$

where $N$ and $q_{p}$ are the number and charge of the proton particles, respectively, $t$ is time, and $I$ is beam intensity. The stronger the intensity in the same period of time, the more the energy of spallation reaction and higher temperature is caused by larger number of the proton particles. So the maximum temperature is always smaller while the beam intensity is $3 \mathrm{~mA}$.

\section{Conclusions}

The paper employs computational fluid dynamics and nuclear physics simulation and obtains the different temperature 


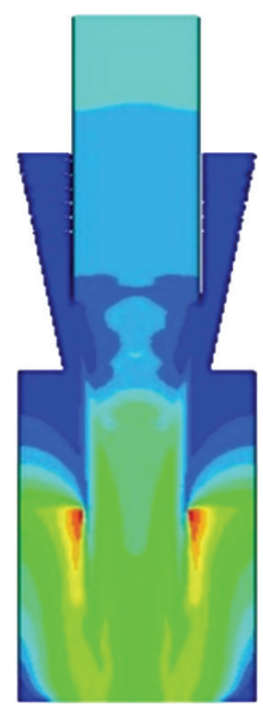

$4 \mathrm{~mA}$

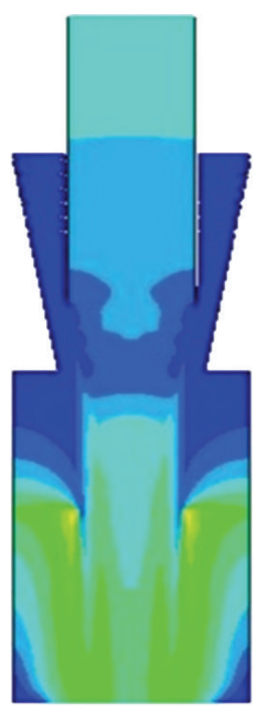

$3 \mathrm{~mA}$

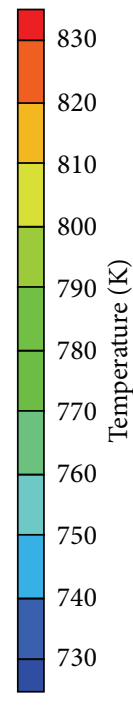

(a) $t=3 \mathrm{~s}$

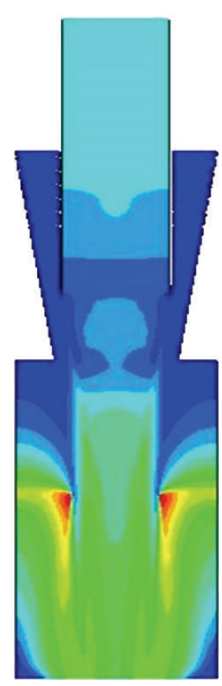

$4 \mathrm{~mA}$

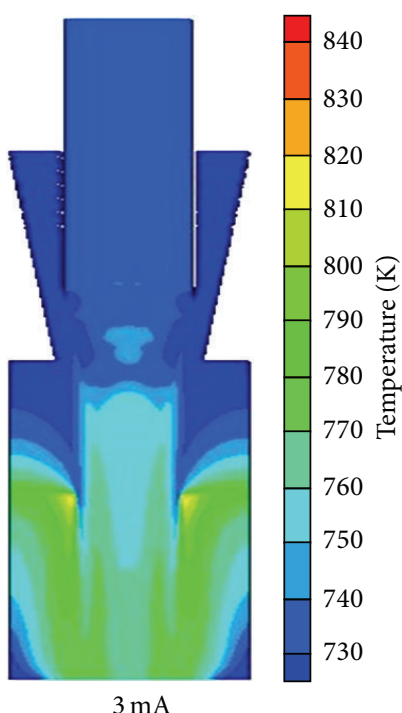

(b) $t=6 \mathrm{~s}$

FIGURE 9: Transient temperature distribution varies with different beam intensity at $t=3 \mathrm{~s}$ and $6 \mathrm{~s}$.

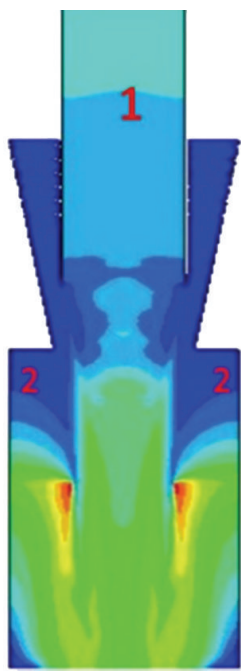

FIgURE 10: Two zones are depicted in the area of the vapor.

distribution in the ADS spallation target while the two values of beam intensity are set.

The CFD provides the phase flow pattern for the nuclear physics simulation and the result provides the heat load for the CFD. The heat load calculated from the nuclear physics simulation is correctly introduced into the CFD calculation and the temperature distribution is obtained finally.

Different beam intensity has little effect on the shape of the temperature distribution while making a big difference to the temperature value. The stronger the intensity is, the larger the temperature gradient is in the area of the vapor.

The maximum temperature varies with different intensity. When the beam intensity is $3 \mathrm{~mA}$, the variation trend is gentler and the maximum temperature eventually reaches about $815 \mathrm{~K}$. On the other hand, while the intensity is $4 \mathrm{~mA}$,

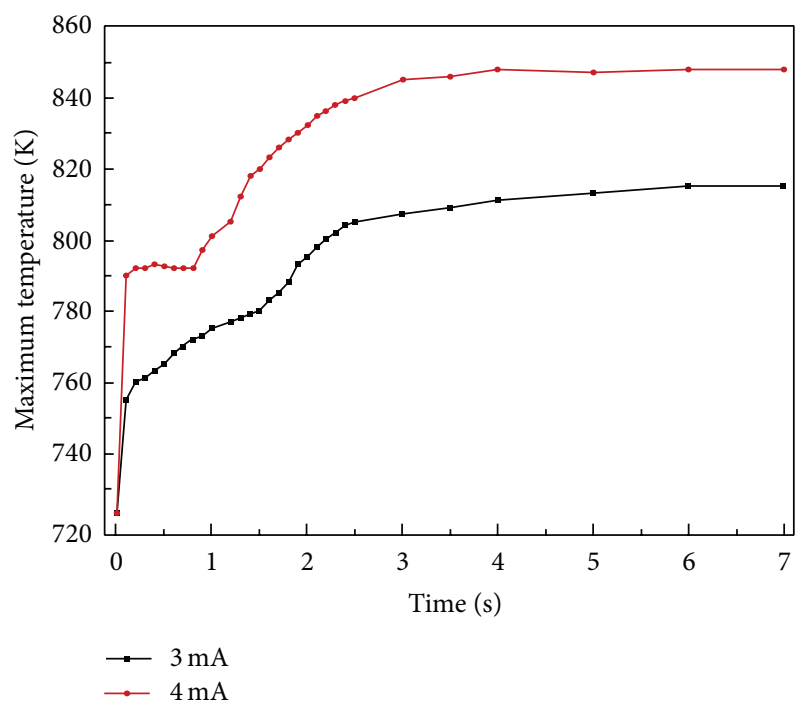

FIGURE 11: Maximum temperature varies with the beam intensity.

the maximum temperature will remain stable for a short time at the beginning and then will rise steadily to about $848 \mathrm{~K}$. It can be inferred that the temperature varies by $4 \%$ per milliampere.

In the future, different proton beam spatial distribution as well as energy can be conducted to provide more complete results and references for the design and optimization of the ADS windowless spallation target.

\section{Conflict of Interests}

The authors declare that there is no conflict of interests regarding the publication of this paper. 


\section{Acknowledgments}

The authors would like to thank Dr. Tian-jiao Liang and Dr. Song-lin Wang of the CAS Institute of High Energy Physics for their great help and support in nuclear physics calculation. This work is financially supported by the National Natural Science Foundation of China (Grant nos. 50936006 and 51276190).

\section{References}

[1] A. G. Class, D. Angeli, A. Batta et al., "XT-ADS Windowless spallation target thermohydraulic design \& experimental setup," Journal of Nuclear Materials, vol. 415, no. 3, pp. 378-384, 2011.

[2] F. Bianchi, R. Ferri, and V. Moreau, "Thermo-hydraulic analysis of the windowless target system," Nuclear Engineering and Design, vol. 238, no. 8, pp. 2135-2145, 2008.

[3] P. K. Nema, "Application of accelerators for nuclear systems: accelerator Driven System (ADS)," Energy Procedia, vol. 7, pp. 597-608, 2011.

[4] V. Mantha, R. Chaudhary, S. Pal et al., "Intense heat simulation studies on window of high density liquid metal spallation target module for accelerator driven systems," International Journal of Heat and Mass Transfer, vol. 49, no. 19-20, pp. 3728-3745, 2006.

[5] A. Borgohain, B. K. Jaiswal, N. K. Maheshwari, P. K. Vijayan, D. Saha, and R. K. Sinha, "Natural circulation studies in a lead bismuth eutectic loop," Progress in Nuclear Energy, vol. 53, no. 4, pp. 308-319, 2011.

[6] C. Cho, Y. Kim, T. Y. Song, and Y. Lee, "Numerical design of a 20 MW lead-bismuth spallation target with an injection tube," Nuclear Engineering and Design, vol. 238, no. 1, pp. 90-101, 2008.

[7] L. Zanini, S. Dementjev, F. Gröschel et al., "Experience from the post-test analysis of MEGAPIE," Journal of Nuclear Materials, vol. 415, no. 3, pp. 367-377, 2011.

[8] M. Vanderhaegen, J. Vierendeels, and B. Arien, "CFD analysis of the MYRRHA primary cooling system," Nuclear Engineering and Design, vol. 241, no. 3, pp. 775-784, 2011.

[9] G. Y. Su, H. Y. Gu, and X. Cheng, "Experimental and numerical studies on free surface flow of windowless target," Annals of Nuclear Energy, vol. 43, pp. 142-149, 2012.

[10] G. Su, X. Chai, H. Gu, and X. Cheng, "Studies on unsteady characteristics of free surface flow in ADS windowless target," Journal of Engineering Thermophysics, vol. 32, no. 9, pp. 15091512, 2011.

[11] F. Roelofs, N. B. Siccama, H. Jeanmart, K. V. Tichelen, M. Dierckx, and P. Schuurmans, "Application of a controlled swirl in the XT-ADS spallation target," in Proceeding of the International Conference on Advances in Nuclear Power Plants (ICAPP '08), Paper 8003, pp. 643-648, Anaheim, Calif, USA, June 2008.

[12] J. N. Reddy and D. K. Gartling, The Finite Element Method in Heat Transfer and Fluid Dynamics, CRC Press, Boca Raton, Fla, USA, 1994.

[13] R. L. Lewis, P. Nithiarasu, and K. N. Seetharamu, Fundamentals of the Finite Element Method for Heat and Fluid Flow, John Wiley and Sons, Chichester, UK, 2004.

[14] K. Arul Prakash, G. Biswas, and B. V. Rathish Kumar, “Thermal hydraulics of the spallation target module of an accelerator driven sub-critical system: a numerical study," International
Journal of Heat and Mass Transfer, vol. 49, no. 23-24, pp. 46334652, 2006.

[15] A. Batta and A. Class, "Free surface modeling and simulation of the water experiment for the XT ADS spa ilation target," in Proceedings of the International Congress on Advances in Nuclear Power Plants (ICAPP '08), pp. 1779-1786, Anaheim, Calif, USA, June 2008.

[16] T. Wang, C. G. Gu, B. Yang et al., "PISO algorithm for unsteady flow field," Journal of Hydrodynamics, vol. 18, pp. 233-239, 2003.

[17] J. Liu, B. Q. Liu, X. Z. Zhang et al., "Flow and phase change process of LBE liquid and vapor in the ADS windowless spallation target," Journal of Engineering Thermophysics, vol. 34, no. 9, pp. 1683-1686, 2013.

[18] J. Liu, L. Gao, H. Chen et al., "Two-way coupling simulation of heat transfer in ADS windowless spallation target," in Proceeding of the 21st International Conference on Nuclear Engineering (ICONE '13), vol. 3 of Paper No. ICONE21-15903, Chengdu, China, July 2013.

[19] J. Liu, L. Gao, and W. Q. Lu, "The influence of adding swirl velocity on height of therecirculation region in ADS windowless spallation target," Journal of Engineering Thermophysics. In press.

[20] http://myrrha.sckcen.be/en/Engineering/Accelerator/Beam_ specifications. 


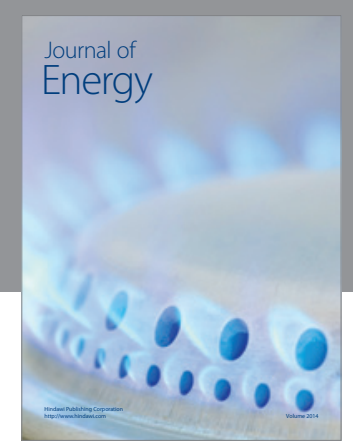

Journal of

Industrial Engineering
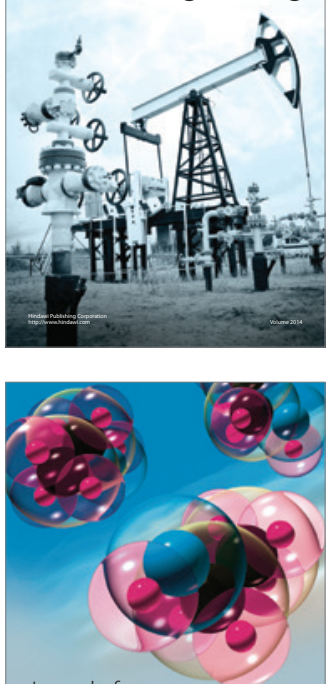

Fuels
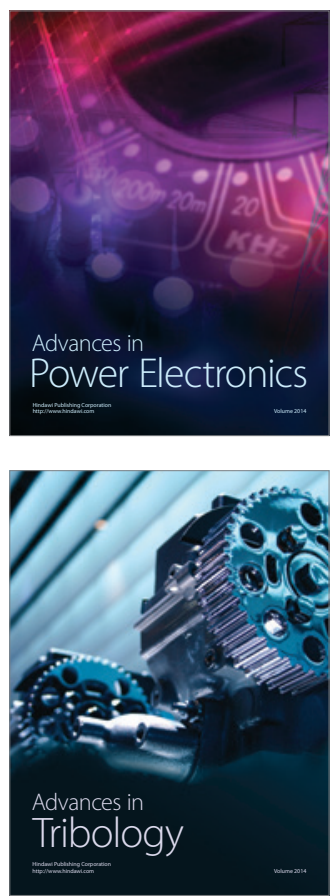

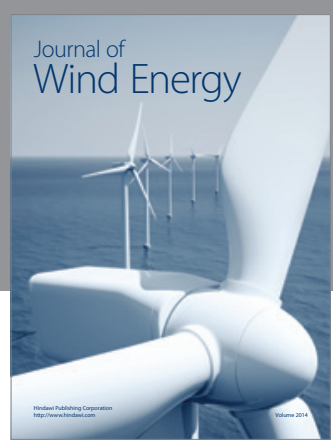

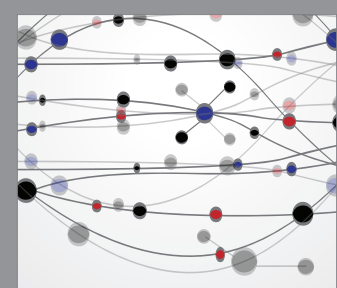

The Scientific World Journal

Submit your manuscripts at http://www.hindawi.com

Journal of

Structures
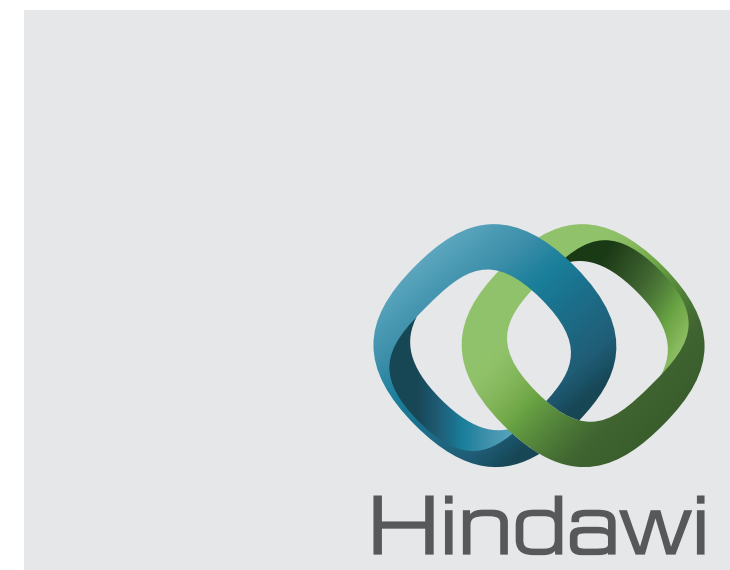

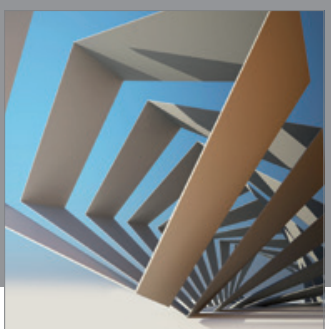

Rotating

Machinery
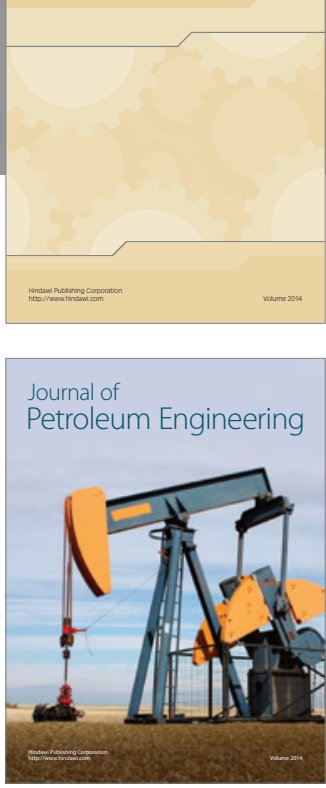

Journal of

Solar Energy
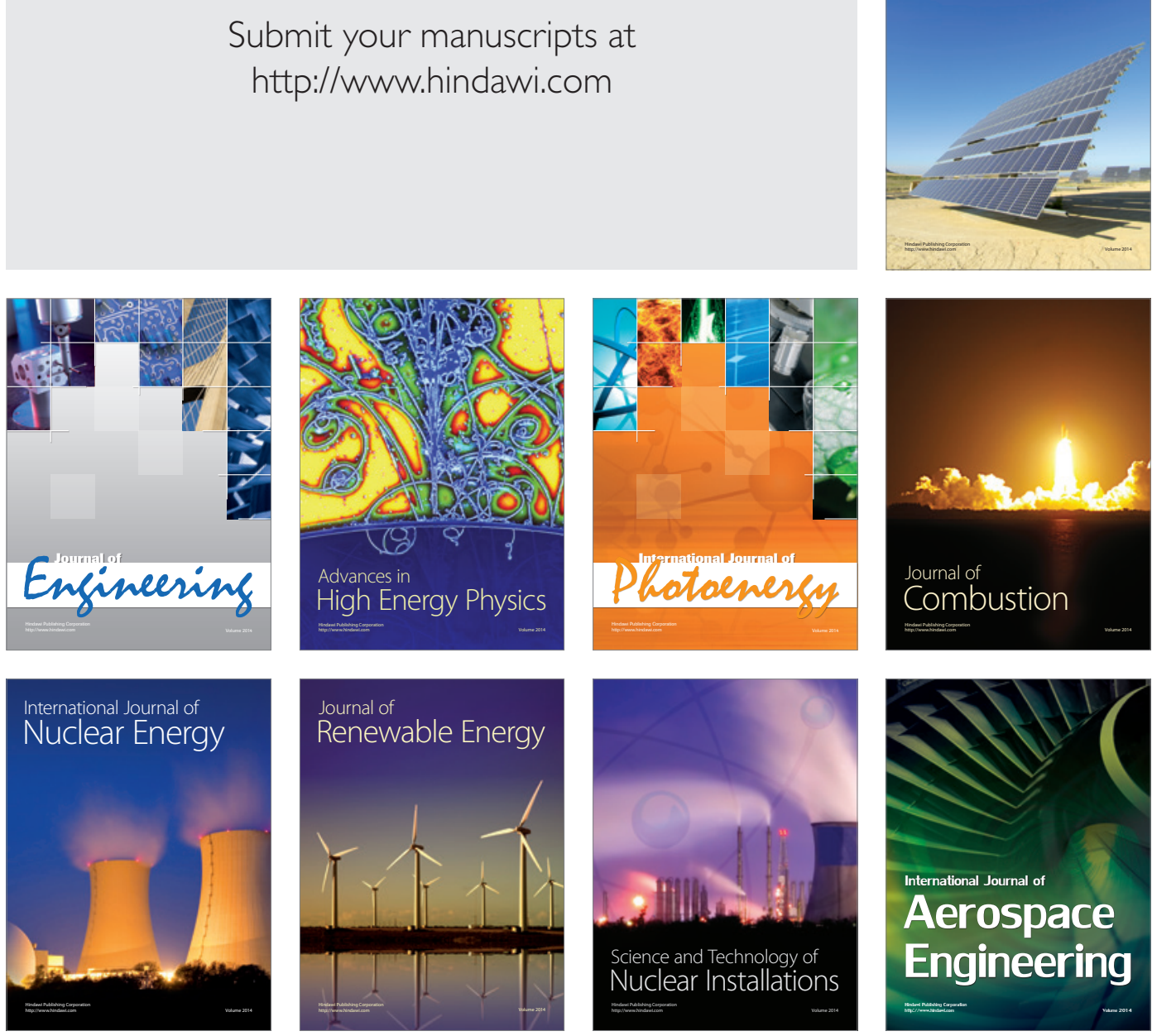